\title{
The Nexus between Entrepreneurship Development and Unemployment: Implication for Economic Growth in Nigeria
}

\author{
Louis S. Nkwatoh ${ }^{1}$ \\ ${ }^{1}$ Department of Economics Yobe State University \\ Correspondence: Louis S. Nkwatoh, Department of Economics Yobe State University, Nigeria. \\ Received: March 17, 2015 \\ Accepted: March 30, 2015 \\ Available online: April 22, 2015 \\ doi:10.11114/aef.v2i2.788 \\ URL: http://dx.doi.org/10.11114/aef.v2i2.788
}

\begin{abstract}
Unemployment and job creation are central to the development agenda in Nigeria especially with the rising rate of youth unemployment resonating within the Country. Strategies and measures have been put in place to curb these appalling rates via a professionalized system of education that will equip individuals with skills and enable them to start up petty enterprises. However, unemployment in Nigeria is appallingly high despite these efforts. This study therefore investigated the nexus between entrepreneurship development and unemployment; and its implication for economic growth in Nigeria. The weighted least square technique was used to estimate the different models with time spans of five and nine years respectively within the period 1982 to 2013. The choice of this technique is driven by its ability to handle regression situations in the presence of non-constant variance (heteroskedasticity). The results established the occurrence of a twin effect: entrepreneurship development reduces future unemployment and also unemployment induces entrepreneurship development. However, the duration of impact is after eight years which is quite long. Finally, the projected rate of unemployment in Nigeria for the year 2018 as established by the study is approximately $29.6 \%$.
\end{abstract}

Keywords: entrepreneurship, unemployment and economic growth

\section{Introduction}

In recent times, unemployment and job creation have been central to the development agenda in both developed and developing Countries especially with the current advent of rising youth unemployment around the world. Nowadays, most strategies to curtail this appalling high unemployment in developing Countries and especially in Nigeria are skewed towards a professionalized system of education that may seemingly equip individuals with skills and enable them to start up petty enterprises (firms).

However, starting up a firm and becoming an entrepreneur is incumbent on an individual's decision, which is the hallmark of the social choice theory. Inferring from the above theory, Blau (1987); Evans \& Leighton (1990) among others, Evans and Jovanovic (1989); Blanchflower \& Meyer (1994) etc, suggest that increasing unemployment will lead to an increase in start-up activities only if the opportunity cost of not starting a firm has decreased. Lucas (1978) and Jovanovic (1982) noted that the unemployed tends to possess lower endowments of human capital and entrepreneurial talents required to start and sustain a new firm; implying that high unemployment is associated with a low degree of entrepreneurial activities (Audretsch, Carree \& Thurik 2001). A low rate of entrepreneurship translates into higher levels of unemployment as a result of low economic growth (Audretsch, 1995).

In Nigeria, the level of unemployment is appallingly high among the youths despite the significant increase in economic growth. However, certain administrative initiatives have been implemented to promote self-dependency that will gainfully generate self-employment through the acquisition of entrepreneurial skills. For instance, the introduction of vocational courses in the educational curriculum in 1997, the creation of the National Directorate of Employment in 1986 charged with the responsibility of promoting skills acquisition, the National Economic Empowerment and Development Strategy designed in 2004 with one of its doctrinal values geared towards fighting unemployment, coupled with election promises (Nkwatoh, 2012). Recently, the government has initiated the YOUWIN program (Youth Enterprise With Innovation In Nigeria) which was part of former President Yaraduas's 20 point agenda which demands government support to entrepreneurship initiatives developed by youths and obtainable through competition.

Despite all the efforts to increase the acquisition of entrepreneurial skills and self reliance, the rate of unemployment in Nigeria still remains high. For instance, a survey by Ayoyinka \& Oluranti (2011) cited in Nkwatoh (2012) shows that, the 
rate of open unemployment was 12\% in March 2006; it rose to 19.7\% in March 2009. According to the 2010 edition of the Labour Force, Sample Survey of the National Bureau of Statistics established a rise in unemployment beyond 20\%.

Thus, the fundamental question that looms in the researcher's mind is whether entrepreneurship development as a strategy to curtail unemployment is apparent in Nigeria or better still; whether soaring unemployment rates can provoke entrepreneurial development in Nigeria.

\section{Theoretical Review}

Scholars have theorized the relationship between unemployment, entrepreneurship and economic growth. However, their theories pose a lot of empirical contentions. The central question to this subject is, "why should an increased amount of entrepreneurial activity impact on unemployment, thereby impacting on economic growth". It can be inferred from literature that the growth of a firm is independent of the size according to Gibrat's Law assertion. The implication of this law is that restructuring of the economy away from large enterprises and towards small ones should have no impact on unemployment (Audretsch et al 2001). Thus the effect of entrepreneurship on unemployment as well as economic growth is neutral. Contrarily, the theory of income choice posits that an increase in unemployment will lead to an increase in start-up-activities. This phenomenon has been commonly tagged as the "Refugee or Shopkeeper" effect. Others have lent credence to the "Schumpeter" effect which establishes a negative relationship between entrepreneurship and unemployment. The premise of this relationship stems from the fact that the unemployed tend to possess lower endowments of human and social capital and entrepreneurial talents required to start and sustain a new firm which may lead to early exit (Thurik, 2007; Lucas, 1978; Baptista, Van Stel \& Thurik, 2006).

Hurst and Lusardi (2004) among others have established that high unemployment may also imply lower levels of personal wealth which reduces the likelihood of self-employment or the survival in the initial stages of business ownership. While some scholars are in accordance with the refugee effect, some have rather taken sides with Schumpeter's effect which emphasizes on a negative relationship between unemployment and entrepreneurship. The latter effect is hard to pin down in Nigeria's case because of limited entrepreneurial opportunities. However, this assertion will only be definite after a succinct analysis of both effects.

\subsection{Literature Review}

Empirically, some studies have taken the position of Gibrat's law. For instance Stel, Thurik and Baljeu (2008) examined the relationship between entrepreneurship (as measured by fluctuations in the business ownership rate) and unemployment in Japan for the period between 1972 and 2002. The overall findings from the vector auto regressive technique showed that the effect of entrepreneurship on unemployment is neutral especially when compared with other OECD countries.

A plethora of literature has demonstrated an inverse relationship between entrepreneurship activities and unemployment in line with the "Schumpeter effect". This conclusion has been simultaneously reached by Garofoli (1994) and Audretsch \& Fritsch (1994) in separate studies who established a negative relationship between unemployment and new-firms, implying that new businesses create employment opportunities leading to a reduction in unemployment. Oladele (2011) using multiple regression, for Nigeria established a negative relationship between employment and entrepreneurship. In the same vein, Salami (2011) concluded that this can only occur if government embarks on some strategies that will promote effective entrepreneurship.

In another related study, Plehn-Dujowich (2012) investigated the dynamic relationship between entrepreneurship, unemployment, and growth for U.S. Industries. His overall findings for about half of the industries tested, showed that entrepreneurship and growth dampened unemployment, while unemployment spurred entrepreneurship and growth, implying that entrepreneurship may be the spark for economic growth in US. Interestingly, the study of Ahmad, Khan \& Mahmood (2011) for Pakistan shows that unemployment is only reduced at the early stage of entrepreneurial activity executed by both males and females.

Some authors have identified education as a catalytic component for the negative relationship between unemployment and entrepreneurship. For instance, Bette (2012) concluded that efficiency and productivity in workplaces require the acquisition of certain basic skills and capacities. Thus, he emphasizes on the need for stronger entrepreneurship education.

Furthermore, studies have established a positive relationship between unemployment and entrepreneurship in accordance with the refugee effect. Evans \& Leighton (1990) in their finding established that unemployment is positively associated with greater propensity to start up a new firm. This finding has been welcomed by (Reynolds, Miller \& Maki, 1995; Reynolds, Storey \& Westhead, 1994) who concluded in their study that greater unemployment serves as a catalyst for start-up activities.

\section{Method}

The dual relationship between entrepreneurship development and unemployment has extensively been investigated 
using a variety of techniques. This study adopted the approach of Audretsch et al., (2001) which considers two separate relationships between unemployment and entrepreneurship and tested two fundamental hypotheses:

i) Entrepreneurship development greatly reduces future unemployment (Schumpeter effect),

ii) Unemployment induces more people towards entrepreneurship development (shopkeeper or refugee effect).

The two equations that investigate these two hypotheses are as follows:

$$
\begin{aligned}
& U_{t}-U_{t-L}=\alpha_{0}+\alpha_{1}\left(E_{t}-E_{t-2 L}\right)+\alpha_{2}\left(U_{t}-U_{2 L}\right)+\varepsilon_{1 t} \\
& E_{t}-E_{t-L}=\beta_{0}+\beta_{1}\left(U_{t}-U_{2 L}\right)+\beta_{2}\left(E_{t}-E_{t-2 L}\right)+\varepsilon_{2 t}
\end{aligned}
$$

Where $\mathrm{U}$ is the unemployment rate, $\mathrm{E}$ is entrepreneurship development (average capacity utilization is used as a proxy in this case because it mirrors trend in entrepreneurship activities) and $\varepsilon$ is a random coefficient. The index $\mathrm{t}$ refers to the year and $\mathrm{L}$ is the time lag in number of years. The expected signs of $\alpha_{1}$ and $\beta_{1}$ are negative and positive.

The equations are estimated using the weighted least squares approach.

One of the common assumptions underlying most process modelling methods, including linear and nonlinear least squares regression, is that the variance of the error term (noise term) is constant over all values of the predictor or explanatory variables (homoskedasticity). However, the magnitude of the noise is not often constant and the data is heteroskedastic. In the presence of heteroskedasticity, even if each noise term is still Gaussian, ordinary least square does not provide efficient estimators. But, if the noise variance at each point (i) is known, then the issue of non-constant variance can be overcome by weighting the observations proportional to the reciprocal of the error variance (see, Gujarati 2004). That is $w_{i}=\frac{1}{\sigma_{i}^{2}}$ gives theoretically correct results for standard errors of coefficients and the various significance tests (Eviews 7 Guide). Thus, given the general regression model:

$$
Y_{t}=X_{t} \beta+\varepsilon_{t}
$$

If $W_{i}=\frac{1}{\sigma_{i}^{2}}$ then $E\left(W_{i} \varepsilon^{\prime} \varepsilon\right)=E\left(\frac{1}{\sigma_{i}^{2}} \varepsilon^{\prime} \varepsilon\right)$

In matrix notation, let $\mathrm{W}$ be a diagonal matrix with diagonal elements equal to $w_{1} \ldots w_{n}$ and let $Y$ and $X$ be the matrices associated with $y_{t}$ and $x_{t}$, then by minimizing the sum of squared standardized errors when weights=1/variance, we obtain the weighted least square (WLS) estimator as:

$$
\hat{\beta}_{W L}=\left(X^{\prime} W X\right)^{-1} X^{\prime} W Y
$$

The main advantage the weighted least square enjoys over other regression methods is its ability to handle regression situations in the presence of non-constant variance. Employing weighted least squares with weights that are inversely proportional to the variance at each level of the explanatory variables yields the most precise parameter estimates possible (Gujurati 2004, Bourbonnais 2004; Wooldridge, 2006). However, this method also suffers from assumption problems. But its principal difficulty in practice is determining values for the weights. The effect of using estimated weights is difficult to assess, but experience indicates that small variations in the weights due to estimation do not often affect a regression analysis or its interpretation (see Carroll and Ruppert 1988; Ryan 1997). Data for this study is extracted from CBN Statistical Bulletin, National Bureau of Statistics website and Nigerian Economic forcast (2014-2050 outlook) http://tradingeconomics.com/nigeria/forcast.

\section{Presentation of Results}

The models are estimated for two different time spans i.e., five and nine years respectively ( $L$ is 5 and 9 ). The choice of lagging the models by five is premised on the fact that, a graduate completes university studies in Nigeria after four years and engages in a one year National Youth Service program (NYC). Therefore, we expect the process of entrepreneurship development to begin in the fifth year. Audretsch et al., (2001) opined that a longer lag structure of at least eight years is more compelling because the employment impact of entrepreneurship is not instantaneous but rather requires a number of years for the firm to grow. However, a lag of nine in this case is chosen based on the robustness of the model.

Tables 1 and 2 show the dynamic relationship between entrepreneurship development and unemployment in Nigeria. Initially different diagnostic tests were employed to ascertain the overall fitness of the model. The Breusch- Godfrey serial correlation LM test, ARCH test, Jacque-Bera normality test and Ramsey RESET specification test have established that the models are robust. Thus, the models are valid for interpretation because, they satisfy the underlying econometric properties i.e., correct functional forms, serially uncorrelated residuals, normally distributed and homoskedasticity. 
Table 1. The effect of change in the rate of unemployment, $U_{t}-U_{t L}$

\begin{tabular}{|c|c|c|c|}
\hline \multirow[t]{2}{*}{ Dependent Variable: $U_{t}-U_{t L}$} & \multicolumn{3}{|c|}{ Lag Structure } \\
\hline & Lag & 5 years & 9 years \\
\hline \multirow[t]{2}{*}{ Constant } & $\beta_{0}$ & -1.844 & 0.534 \\
\hline & & $(-0.012)$ & $(0.0001)$ \\
\hline \multirow{2}{*}{$E_{t}-E_{2 L}$} & $\beta_{1}$ & -0.040 & -0.204 \\
\hline & & $(0.580)$ & $(0.031)^{* *}$ \\
\hline \multirow[t]{2}{*}{$U_{t}-U_{2 L}$} & $\beta_{2}$ & -0.0747 & 0.662 \\
\hline & & $(0.690)$ & $(0.196)$ \\
\hline R-squared & & 0.70 & 0.65 \\
\hline Durbin Watson & & 2.30 & 1.8 .3 \\
\hline
\end{tabular}

Diagnostic Checking (lag 5 years): JB $=2.11$ [0.517]; LM $(2)=1.85$ [0.395]; ARCH $(2)=$ 0.004[0.995]; White Heteroskedasticity $=0.947$ [0.472]; Ramsey RESET $=0.271(0.51)$

Diagnostic Checking (lag 9 years): JB $=0.71[0.62]$; $\mathrm{LM}(2)=2.54[0.715]$; $\mathrm{ARCH}(2)=$ $0.162[0.851]$; White Heteroskedasticity $=0.020$ [0.932];Ramsey RESET $=0.244(0.78)$

** indicates 0.05 significance level. Probability values are quoted in square brackets. The weighting variable is entrepreneurship (average capacity utilization) lagged by nine years.

In Table 1, the explanatory powers (R-Squared) of both periods are good enough. Using five years lag, entrepreneurship development has the potentials of reducing subsequent unemployment rates in Nigeria. But as time goes on, entrepreneurship development significantly reduces subsequent unemployment by 0.204 units as established when using a time lag of nine years. The expected signs thus, lend credence to the "Schumpeter Effect" (entrepreneurship development reduces unemployment) and further corroborates the submission of Audretsch et al (2001) that entrepreneurship is not instantaneous but rather requires a number of years for firms to grow.

Table 2. The Effect of Change In The Rate of Entrepreneurship Development, $E_{t}-E_{t L}$

\begin{tabular}{lllll}
\hline \multirow{2}{*}{ Dependent Variable: $E_{t}-E_{t L}$} & \multicolumn{2}{l}{ Lag Structure } & \\
& Lag & 5 years & 9 years \\
\hline Constant & $\alpha_{0}$ & 4.848 & 3.965 \\
& & $(0.001)^{* *}$ & $(0.0009)$ \\
& $\alpha_{t}-U_{2 L}$ & 1.062 & 0.726 \\
& & & $(0.0075)^{* *}$ & $(0.817)$ \\
& $E_{t}-E_{2 L}$ & $\alpha_{2}$ & 0.652 & 0.201 \\
& & $(0.0008)^{* *}$ & $(0.002)^{* *}$ \\
R-squared & & 0.65 & 0.45 \\
Durbin Watson & & 1.8 & 1.7
\end{tabular}

Diagnostic Checking (lag 5 years): $1 \mathrm{JB}=0.75[0.684]$; LM (2) $=4.3$ [0.116]; ARCH (2) $=0.004[0.995]$;

White Heteroskedasticity $=0.51[0.730]$; Ramsey RESET $=2.74(0.0912)$

Diagnostic Checking (lag 9 years): JB $=3.54$ [0.169]; LM (2) = 3.2 [0.052]; ARCH (2) $=0.005[0.943]$;

White Heteroskedasticity $=0.354[0.837]$;Ramsey RESET $=2.01(0.173)$

** indicates 0.05 significance level. Probability values are quoted in square brackets. The weighting variable is entrepreneurship (average capacity utilization) lagged by nine years.

\footnotetext{
1 ARCH denotes LM-type Breusch-Godfrey Serial Correlation LM and ARCH tests, respectively, to test for the presence of serial correlation and ARCH effect. JB and RESET stand for Jarque-Bera Normality Test and Ramsey Regression Specification Error Test, respectively.
} 
Table 2 establishes a negative effect between unemployment and entrepreneurship development using five years lag. That is, changes in unemployment significantly reduce entrepreneurship development by 0.0075 units. The implication here is that, the more people are unemployed, the more they lack the opportunities. This leads to idleness, undesirable activities, wasteful talents and valuable skills, energy and time among the vulnerable group (see Nkwatoh 2012). However, the estimated model with a lag period of nine years shows that changes in unemployment have a positive and insignificant impact on subsequent self-employment. The expected sign is consistent with the "Refugee or Shopkeeper Effect" (unemployment stimulates entrepreneurship development). The result of this last model supports an earlier finding by Audretsch et al (2001) suggesting that positive effects are larger when longer time lags are incorporated. Perhaps, the longer time lags may also reflect the frustration period of getting a white collar job by the unemployed to the time they start thinking of becoming self-employed, as may be the case in Nigeria.

\subsection{Implication for Economic Growth}

The implication of the nexus between entrepreneurship development and unemployment in Nigeria is far reaching. The two results show the dynamic inter-temporal relationships of the Schumpeter and Shopkeeper effects in Nigeria. The Schumpeter effect simply suggests that in long-run, newer products will be generated by new and small firms via the process of entrepreneurship development; leading to greater competition in the market, which will in turn increase the purchasing power of consumers, thereby surging economic growth as well as reducing unemployment levels.

This totally contradicts Gibrat's "Law of Proportional Effect" that, restructuring the economy away from large enterprises and towards small ones should have no impact on the unemployment rate.

Based on the estimated coefficients for model one, projections can be made regarding the level of future unemployment in Nigeria for 2018 (another five years after graduation and NYSC program): $U_{t}-U_{t L}=6.4$ for $\mathrm{t}=2018$ and $\mathrm{L}=5$; this would suggests that unemployment will rise within a period of five years starting in 2013 reaching approximately $29.6 \%$ in 2018. This high rate is very crucial and may undermine the economic stability of the Country. However, the calculations depend upon the validity of equation (1) thus; the interpretation of this result needs extra care; since multiple factors account for unemployment in Nigeria.

The Shopkeeper effect also implies that economic growth will increase when unemployment starts impacting positively on entrepreneurship. However, the duration of impact for both effects is reasonably high. This can make the vulnerable class to lose focus within the period of unemployment, consequently lagging economic growth.

\section{Concluding Remarks}

Unemployment and job creation are central to the development agenda in Nigeria especially with the rising rate of youth unemployment resonating within the Country. Strategies and measures have put in place to curtail these appalling rates via a professionalized system of education that will equip individuals with skills and enable them to start up petty enterprises. Despite all the efforts to increase the acquisition of entrepreneurial skills and self reliance, the rate of unemployment in Nigeria is awfully high; accompanied by low levels of entrepreneurial development. In this light, this study investigated the nexus between entrepreneurship development and unemployment and its implication for economic growth in Nigeria.

The empirical findings of this study lend credence to the occurrence of a twin effect (Schumpeter and Shopkeeper) in Nigeria. However, these effects are not instantaneous and only start impacting positively after a longer duration of eight years. Finally, the projected value of unemployment rate in Nigeria for the year 2018 has been established in this study; approximated at $29.6 \%$.

A possible recommendation to these findings is that the government and stakeholders should create ample opportunities (in the form of new firms, new ideas, knowledge-based economic activities, self-reliant activity programs etc.) which will be immediately ready for the unemployed especially when they leave school. This will shorten the lagged length of effects, curtail future rise in unemployment rates; thereby speeding up the economic growth of Nigeria. Furthermore, the occurrence of the Schumpeter effect in Nigeria shows that the youths should avail themselves of the existing entrepreneurial opportunities and more specifically, the government and non-governmental organizations should support innovative and creative ideas among the group, since this will fully engage their time, energy, talents, efforts etc, thus deterring them from undesired activities and social malpractices.

\section{References}

Ahmad, H., Khan, K., \& Mahmood, I. (2011). Entrepreneurship, Unemployment and Economic Growth. Business and Management Review, 1(8). ISSN: 2047 Available online at http://www.businessjournalz.org/bmr

Audretsch, D., B., \& Michael, F. (1994). The Geography of Firm Births in Germany Regional Studies, 28(4), 359-365.

Audretsch, D., \& Thurik, A.( 2001). What is New about the New Economy: Sources of Growth in the Managed and Entrepreneurial Economies. Industrial and Corporate Change, 19, 795-821. 
Audretsch, B., Carree, A., \& Thurik, R. (2001), Does self-employment reduce unemployment? Discussion paper TI01-074/3, Tinbergen Institute, Erasmus University Rotterdam.

Audretsch, B., Klomp, L., Santarelli, E., \& Thurik, R. (2004). Gibrat's Law: are the services different? Rev. Ind. Organ, 24, 301-324.

Baptista, R., Thurik, R., \& Van Stel, J. (2006) The relationship between entrepreneurship and unemployment in Portugal, Technological Forecasting \& Social Change, 74, 75-89.

Baptista, R., \& Thurik. R. (2007). The relationship between entrepreneurship and unemployment: Is Portugal an outlier? Technological Forecasting \& Social Change, 74, 75-89.

Bette, E. (2012). Enhancing the Entrepreneurship Education in Nigeria. American Journal of Social Issues \& Humanities, 2(4), 232-239

Blanchflower, D., \& Meyer, B. (1994). A Longitudinal Analysis of Young Entrepreneurs in Australia and the United States. Small Business Economics, 6(1), 1-20.

Blau, D. (1987). A Time Series Analysis of Self Employment in the United States, Journal of Political Economy, 95(3), 445- 467.

Bourbonnais, R. (2004). Manuel et excercises corrigés. $4^{\mathrm{e}}$ edition Dunod, Paris.

Evans, D., \& Jovanovic, B. (1989). Estimates of a Model of Entrepreneurial Choice under Liquidity Constraints, Journal of Political Economy, 97(3), 657-674.

Evans, D, \& Leighton, S. (1989). The Determinants of Changes in U.S. Self-Employment, 1968-1987. Small Business Economics, 1(2), 111-120.

Hurst, E., \& lusardi, A. (2004). Liquidity Constraints,Household Wealth and Entrepreneurship. Journal of Political Economy, 112(2), 319-347.

Garofoloi, G. (1994). New Firm Formationand Regional Development: The Italian Case. Regional Studies, 28(4), 381-394.

Gujarati, D. (2004). Essentials of Econometrics, $4^{\text {th }}$ ed., McGraw-Hill,New York

Lucas, R. (1978). On the Size Distribution of Business Firms. Bell Journal of Economics, 9, 508-523.

Nkwatoh, L. (2012). Forecasting Unemployment Rates In Nigeria: Using Univariate Time Series Models. Paper presented at the 53th Annual Conference of the Nigerian Economic Society.

Oladele, P., Akeke, I., \& Oladunjoye, O. (2011). Entrepreneurship Development:A Panacea for Unemployment Reduction in Nigeria. Journal of Emerging Trends in Economics and Management Sciences (JETEMS), 2(4), 251-256.

Plehn-Dujowich, J. (2012). The Dynamic Relationship between Entrepreneurship, Unemployment, and Growth: Evidence from U.S. Industries. Plehn Analytical Economic Solutions, LLC, Willow Grove. Under contract number SBAHQ-10-M-0204.

Reynolds, P., Miller B., \& Maki, M. (1995). Explaining Regional Variation in Business Births and Deaths: U.S. 1976-1988. Small Business Economics, 7(5), 389-707.

Reynolds, P. et al (1994). Cross-National Comparisons of the Variation in New Firm Formation Rates. Regional Studies, 28(4), 443-456.

Salami, C. (2011). Entrepreneurial Interventionism and Challenges of Youth Unemployment in Nigeria. Global Journal of Management and Business Research, 11(7).

Stel, A.,Thurik, R., Baljeu, L., \& Verheul, I. (2008). The Relationship between Entrepreneurship and Unemployment in Japan. Discussion Papers on Entrepreneurship, Growth and Public Policy

Thurik, R. (2003). Entrepreneurship and unemployment in the UK. Scottish Journal of political Economy, 50(2), 264-290.

Wooldridge, J. (2006). Introductory Econometrics: A Modern Approach. (3rdEdition). Thomson South-Western, USA

\section{$(\mathrm{cc}) \mathrm{BY}$}

This work is licensed under a Creative Commons Attribution 3.0 License. 